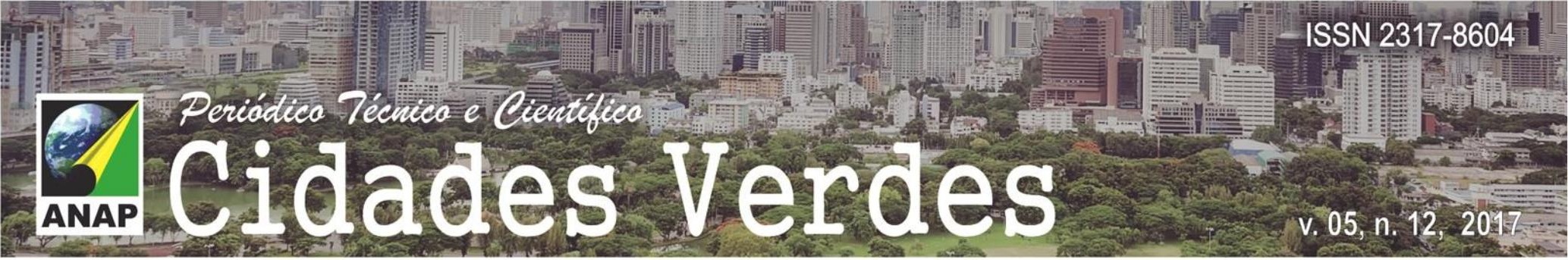

\title{
Viabilidade Do Uso De Biogás Como Fonte De Energia Renovável Em Aterros Sanitários
}

Viability Of The Use Of Biogas As A Renewable Energy Source In Sanitary Land

Viabilidad Del Uso De Biogas Como Fuente De Energía Renovable En Autos Sanitarios

Yara Campos Miranda

Mestranda em Engenharia Urbana, UEM, Brasil

Yaracamposmiranda1@gmail.com

Francisco Ferreira Martins Neto

Mestrando em Ciência e Tecnologia Ambiental, UFTM, Brasil neto.fm@gmail.com 


\section{RESUMO}

O exacerbado crescimento das cidades associado a uma demanda cada vez maior por recursos energéticos fazem com que sejam necessárias a avaliação da viabilidade de outras energias alternativas, visando suprir a necessidade antrópica com o menor impacto ambiental possível.Com a utilização de biogás para geração de energia têm-se vantagens, pois o mesmo é uma fonte renovável e limpa, partindo do princípio que a produção de resíduos ocorre continuamente. Assim faz-se a substituição de derivados do petróleo, captação e utilização de gases poluentes (metano), e comercialização de créditos de carbono. Assim, este trabalho tem como objetivo. uma revisão bibliográfica sobre o tema, no qual se pretende esclarecer estas e outras questões advindas da produção de energia elétrica proveniente do uso do biogás, considerando informações da matriz elétrica brasileira. Conclui-se que com o surgimento de novas tecnologias, é possível que o aproveitamento do biogás se torne viável, porém é fundamental a participação de prefeituras em políticas públicas eficientes de coleta seletiva para melhorar a qualidade do biogás produzido no aterro, além de incentivos financeiros para a implantação de novos projetos. Portanto, se faz necessário novos estudos nesta área de grande importância ambiental, haja visto que os resíduos sólidos urbanos causam danos ao ambiente, e possuem poder de aproveitamento energético.

PALAVRAS-CHAVE: Aproveitamento Energético; Energia Limpa; MDL.

\section{ABSTRACT}

The exacerbated growth of cities associated with an increasing demand for energy resources makes it necessary to evaluate the viability of other alternative energies, aiming to supply the anthropic need with the lowest possible environmental impact. With the use of biogas for power generation there are advantages because it is a clean and renewable source, assuming that the production of waste occurs continuously. This is done by replacing petroleum derivatives, collecting and using polluting gases (methane), and trading carbon credits. Thus, this work aims to. a literature review on the subject, in which it is intended to clarify these and other issues arising from the production of electricity from the use of biogas, considering information from the Brazilian electricity matrix. It is concluded that with the emergence of new technologies, it is possible that the biogas utilization becomes feasible, but it is fundamental the participation of municipalities in efficient public policies of selective collection to improve the quality of the biogas produced in the landfill, besides financial incentives for the implementation of new projects. Therefore, it is necessary to carry out new studies in this area of great environmental importance, since urban solid waste causes damage to the environment, and has power to use energy.

KEY WORDS: Energy Utilization; Clean energy; MDL;

\section{RESUMEN}

El exacerbado crecimiento de las ciudades asociado a una demanda cada vez mayor por recursos energéticos hace que sea necesaria la evaluación de la viabilidad de otras energías alternativas, con el fin de suplir la necesidad antrópica con el menor impacto ambiental posible. Con el uso de biogás para generación de energía se tienen ventajas, pues lo mismo es una fuente renovable y limpia, partiendo del principio que la producción de residuos ocurre continuamente. Así se hace la sustitución de derivados del petróleo, captación y utilización de gases contaminantes (metano), y comercialización de créditos de carbono. Así, este trabajo tiene como objetivo. una revisión bibliográfica sobre el tema, en el que se pretende aclarar estas y otras cuestiones derivadas de la producción de energía eléctrica proveniente del uso del biogás, considerando informaciones de la matriz eléctrica brasileña. Se concluye que con el surgimiento de nuevas tecnologías es posible que el aprovechamiento del biogás se haga viable, pero es fundamental la participación de prefecturas en políticas públicas eficientes de recolección selectiva para mejorar la calidad del biogás producido en el relleno, además de incentivos financieros para la implantación de nuevos proyectos. Por lo tanto, se hace necesario nuevos estudios en esta área de gran importancia ambiental, ya que los residuos sólidos urbanos causan daños al ambiente, y poseen poder de aprovechamiento energético.

PALABRAS CLAVE: Aprovechamiento Energético; Energía limpia; MDL. 


\section{INTRODUÇÃO}

O crescimento populacional impacta significativamente para a geração de resíduos sólidos urbanos, que possuem relação direta com a qualidade de vida humana e ambiental. Esses resíduos são advindos das diversas atividades antrópicas, e muitas vezes são descartados de maneira errônea, o que acarreta em danos aos ecossistemas.

Muitas cidades não possuem tratamento adequado, depositando seus resíduos em lixões. Uma das soluções mais latentes para evitar este processo foi tomada por meio da aprovação da Política Nacional dos Resíduos Sólidos (PNRS) em 02/08/2010, após mais de 20 anos em trâmite no Congresso Nacional (MMA, 2010).Esta legislação prevê que todos os municípios adotem aterros sanitários, sendo uma forma de disposição que visa, juntamente com a coleta seletiva, tratamento adequado.

Os aterros são responsáveis por grande parte das emissões de gás metano na atmosfera, ocasionando um grande problema, visto que o mesmo é 21 vezes mais prejudicial se comparado ao dióxido de carbono. Além disso, tem-se a formação do chorume, líquido proveniente de resíduos sólidos; resultado principalmente da água de chuva que se infiltra no lixo carregando substancias provenientes da decomposição biológica da parte orgânica dos resíduos sólidos, altamente poluidor (SILVA; CAMPOS, 2008).

Em decorrência da disposição do resíduo sólido, ao longo do tempo, ocorre a geração do biogás, proveniente da decomposição da matéria orgânica, com características variáveis, dependendo do material que foi disposto no aterro, tendo como principais componentes o dióxido de carbono $\left(\mathrm{CO}_{2}\right)$ e o metano $\left(\mathrm{CH}_{4}\right)$.

A conversão energética do biogás pode ser apresentada como uma solução para o grande volume de resíduos produzidos por atividades agrícolas e pecuárias, destilarias, tratamento de esgotos domésticos e aterros sanitários, visto que reduz o potencial tóxico das emissões de metano ao mesmo tempo em que produz energia elétrica, agregando, desta forma, ganho ambiental e redução de custos (COSTA, 2002).

Ainda o MMA (2010) afirma que o Brasil destaca-se no cenário internacional no rol de países que aplicam o Mecanismo de Desenvolvimento Limpo (MDL), um dos instrumentos do Protocolo de Quioto criados para ajudar os países desenvolvidos a alcançar suas metas de redução de emissões de carbono e incentivar financeiramente os países em desenvolvimento.

Dos 168 projetos de MDL registrados em diversos setores no Brasil, 25 são realizados em aterros sanitários. Destes, apenas 7 foram registrados com intuito de geração de energia, constituindo-se uma oportunidade promissora para promover a sustentabilidade social e ambiental do desenvolvimento municipal no país, por meio do estímulo a uma gestão mais apropriada dos resíduos sólidos urbanos (MMA, 2010).

Assim, é possível perceber a potencialidade do resíduo para produção de energia, principalmente no que tange a aterros sanitários, desde que ocorra análise da viabilidade da implementação devido os aspectos ambientais e custos do empreendimento. Este trabalho tem como finalidade uma revisão bibliográfica sobre o tema, no qual se pretende esclarecer estas e outras questões advindas da produção de energia elétrica proveniente do uso do biogás, considerando informações da matriz elétrica brasileira 


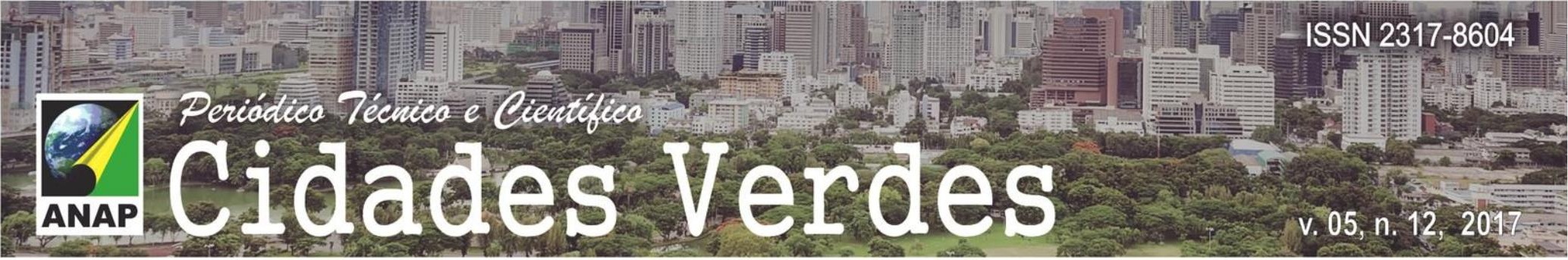

\section{PROCESSO DE PRODUÇÃO DE ENERGIA}

A geração do biogás ocorre em quatro principais fases na vida útil de um aterro sanitário. $\mathrm{Na}$ primeira, há a degradação através do processo aeróbio, que produz $\mathrm{CO} 2$ e altas quantidades de N2, que posteriormente sofrem declínio nas fases subsequentes. Após isso, observa-se o esgotamento de $\mathrm{O} 2$, propiciando anaerobismo, com a produção de metano e redução de $\mathrm{CO} 2$ produzido. Na fase final há uma produção estável de CH4, CO2 e N2 (EPE, 2008).

Em aterros sanitários, após o fechamento das células, a decomposição é realizada de maneira anaeróbia e a produção de biogás atinge o ápice após um a dois anos, decrescendo continuamente até cerca de 20 anos após o fechamento. A capacidade de geração de biogás em um aterro depende de fatores como a composição do resíduo depositado, a umidade e o pH (FIGUEIREDO, 2007).

Estes empreendimentos devem estar equipados com um sistema de captação de gases, dimensionado juntamente com as células no momento de aquisição do projeto do aterro. Normalmente, estes gases são tratados através de queimadores denominados flares, que possuem a finalidade de transformar os gases oriundos da decomposição da matéria orgânica em menos agressivos ao meio ambiente (LANDIN; AZEVEDO, 2008).

Para a produção de energia (figura 1), o aterro deve possuir poços bem distribuídos para extração do biogás por exaustão forçada (pressão negativa), uma rede de drenos conectados ao topo dos poços. Neste sistema, a captação do biogás pode chegar a $80 \%$. Posteriormente, o composto é transportado até uma unidade de tratamento, equipada por um conjunto de exaustores e filtros, com a finalidade de remover condensados e particulados, protegendo assim o gerador (CANDIANE; SILVA, 2011).

Figura 1: Processo de conversão do biogás após sua coleta no aterro sanitário

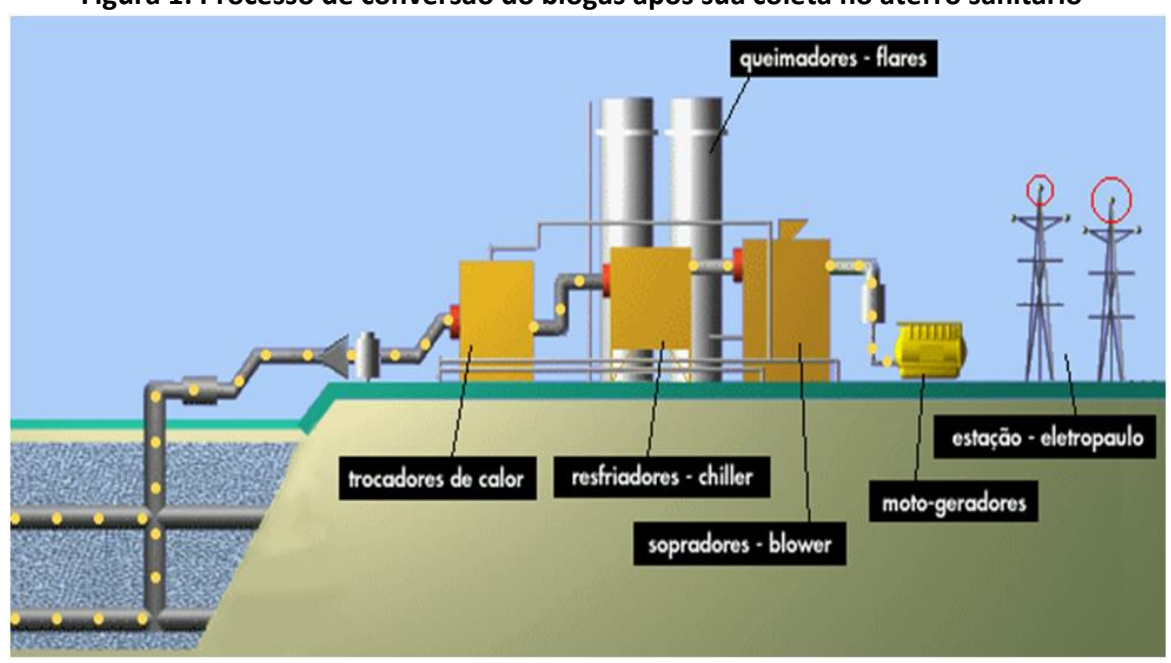

Fonte: SUSTENTARE AMBIENTAL (2015)

De acordo com a CENBIO (2005), os motores de combustão interna (Ciclo de Otto) são os mais utilizados para conversão energéticas, pois os mesmos possuem maior eficiência, além de menores custos. Já as turbinas a gás, quando são operadas em cogeração (calor e eletricidade), 


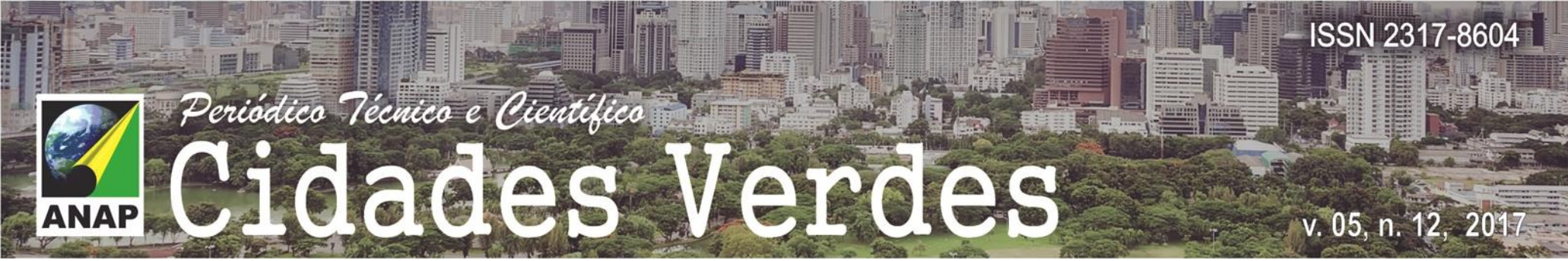

possuem maior eficiência global de conversão, porém são menos usuais, devido ao fato de serem equipamentos importados com alto valor e custos de manutenção e operação elevados. EPE (2008), acrescenta que mesmo alimentados com combustível de poder calorifico baixo, o rendimento pode ser superior aos $35 \%$.

Vale ressaltar que é importante a realização de monitoramento da qualidade do gás, haja visto que existem variáveis que podem prejudicar o sistema. Assim, também e possível a implantação de medidas mitigadoras, caso o empreendimento, mesmo com a utilização do biogás ainda esteja contaminando o meio ambiente com compostos nocivos (SILVA; CAMPOS, 2008).

\section{EMPREENDIMENTOS A BIOGAS DE ATERRO NO BRASIL}

De acordo com a Agencia Nacional de Energia Elétrica - ANEEL (2015), existem 11 empreendimentos cadastrados em operação no Brasil que produzem energia elétrica através do biogás de Resíduos Sólidos Urbanos (Tabela 1), totalizando 73.953 kW de potência outorgada.

Tabela 1 - Matriz Energética brasileira de geradores de energia elétrica através do biogás produzido em aterro sanitário cadastrados na ANEEL.

\begin{tabular}{|c|c|c|c|}
\hline Usina & Potência (kW) & Destino & Município \\
\hline Salvador & 19.730 & PIE & Salvador - BA \\
\hline $\begin{array}{l}\text { São João } \\
\text { Biogás }\end{array}$ & 24.640 & PIE & São Paulo - SP \\
\hline Energ-Biog & 30 & REG & Barueri - SP \\
\hline Asja BH & 4.278 & REG & $\begin{array}{l}\text { Belo Horizonte - } \\
\text { MG }\end{array}$ \\
\hline Arrudas & 2.400 & REG & $\begin{array}{l}\text { Belo Horizonte - } \\
\text { MG }\end{array}$ \\
\hline Ambient & 1.500 & REG & $\begin{array}{c}\text { Ribeirão Preto - } \\
\text { SP }\end{array}$ \\
\hline $\begin{array}{l}\text { Biotérmica } \\
\text { Recreio }\end{array}$ & 8.556 & PIE & $\begin{array}{c}\text { Minas de Leão - } \\
\text { RS }\end{array}$ \\
\hline Uberlândia & 2.852 & REG & Uberlândia - MG \\
\hline $\begin{array}{l}\text { CTR Juiz de } \\
\text { Fora }\end{array}$ & 2.852 & REG & Juiz de Fora- MG \\
\hline Itajaí Biogás & 1.065 & REG & Itajaí - SC \\
\hline Bandeirantes & 4.624 & REG & São Paulo - SP \\
\hline Total & 73.953 & & \\
\hline
\end{tabular}

Legenda: PIE: Produção Independente de Energia; REG: Registro

Considerando as unidades em operação, nota-se que a maioria localiza-se na região sudeste do país, abrangendo 8 empreendimentos nos estados de São Paulo e Minas Gerais, com 4 usinas em cada um. Vale ressaltar, que ainda existem duas usinas em construção em Barueri - SP e Cabo Verde - SP, que quando iniciarem o processo de conversão de energia acrescentarão $49.547 \mathrm{~kW}$ de potência na matriz energética brasileira. Também nota-se que apenas 3 são 
produtoras independentes de energia (PIE), o restante ainda encontra-se em processo de registro.

Ao constatar que uma residência média brasileira consome $300 \mathrm{kWh}$ por mês, e em um ano esse índice alcança $3600 \mathrm{kWh}$, e a potência total dos 11 empreendimentos a biogás instalados em aterros urbanos de $73.953 \mathrm{~kW}$, em um ano de funcionamento continuo, é obtido 638.953.920.Essa produçãoabasteceria, com energia elétrica 177.487 residências, o que poderia, junto com outras alternativas, diversificar a matriz energética brasileira, propiciando a menor utilização de combustíveis fósseis para a geração de energia.

O Brasil gera 183,5 mil toneladas de resíduos sólidos por dia, totalizando 66.977 .500 ton/ano.Considerando que $51,4 \%$ desse resíduo seja matéria orgânica, obtém-se aproximadamente $29,6 \mathrm{~m}^{3}$ de biogás por tonelada de resíduo). Portanto, se toda essa matéria orgânica fosse destinada a aterros sanitários, seria obtida uma média de $1.982 .534 .000 \mathrm{~m}^{3} \mathrm{de}$ biogás em um ano. $O$ poder calorífico do biogás proveniente de aterros sanitários,em média, é de $5.600 \mathrm{kcal} / \mathrm{m}^{3}$, que resulta numa geração equivalente a $1,43 \mathrm{kWh} / \mathrm{m}^{3}$ (FIGUEIREDO, 2007). Dessa forma, o potencial de produção nacional de energia elétrica a partir do biogás de aterros sanitários chegaria a $2.835 .023 .620 \mathrm{kWh} /$ ano, possibilitando o equivalente ao abastecimento de 787.506 residências. Isso significa que apenas $25,2 \%$ do potencial estimado estariam sendo aproveitados.

Pedott e Aguiar (2014) observaram que o aterro sanitário de Bandeirantes já foi considerado o maior do Brasil, e quando se implantou o sistema de biogás, pretendia-se gerar 20MW de eletricidade. Entretanto, Costa Junior (2012) constatou que o projeto de geração de energia apresentou erros de dimensionamento graves, o que acarretou em perdas financeiras, devido a elevados custos de produção.

O aterro sanitário Sítio São João, possui potência instalada de 26.640 kW (ANEEL, 2015), que atualmente é o maior produtor de energia através do biogás do país. Foi desativado em 2009 e recebeu 25 milhões de toneladas de resíduos. Estudos de viabilidade da época demonstravam alto potencial de produção de biogás, porém após instalado, Pedott e Aguiar (2014) notaram que o potencial de produção deste composto é $52 \%$ menor do que o previsto, demonstrando assim que o projeto terá lucros bem menores do que o esperado.

Em uma pesquisa realizada por Souza, Horttanainen e Antonelli (2014) em 16 cidades brasileiras, a matéria orgânica representava $51,5 \%$ na composição dos resíduos sólidos depositados nos aterros verificados. Considerando o potencial de produção de biogás, seria possível gerar uma quantidade de 480,120 GWh utilizando métodos eficientes de aproveitamento energético.A cidade de São Paulo, por exemplo, poderia produzir $637 \mathrm{GWh}$ com o gás de aterros. Se todos os compostos presentes sofressem processo de separação antes de serem depositados nos aterros, esta eficiência poderia ser aumentada em até um terço.

Assim, se faz necessários estudos de aperfeiçoamento do método de estimativa de produção do gás, e adequação a realidade brasileira, muitos modelos utilizados atualmente se baseiam em características de países europeus, que transmite dados errôneos e equivocados. Além disso, estudos de viabilidade devem incorporar riscos financeiros, caso haja discrepância da realidade com o estudado. (PEDOTT; AGUIAR, 2014)

\section{VANTAGENS E DESVANTAGENS AMBIENTAIS}

Com a utilização de biogás para geração de energia têm-se vantagens, pois o mesmo é uma fonte renovável e limpa, partindo do princípio que a produção de resíduos ocorre 
continuamente. Assim faz-se a substituição de derivados do petróleo, captação e utilização de gases poluentes (metano), e comercialização de créditos de carbono. $\mathrm{O}$ biogás produzido no aterro pode ser utilizado como combustível em sistemas de geração de energia elétrica, proporcionando ao aterro economia com os gastos com energia elétrica adquirida da rede, proveniente de concessionária local, e receita com a venda de energia excedente (CENBIO, 2005; ROYA et al., 2007).

Salomon e Lora (2005) ainda afirmam que quando se trata de produção de energia elétrica, ainda podem-se elencar outras vantagens, como a geração descentralizada e próxima aos pontos de carga, haja visto que aterros sanitários em sua grande maioria se localizam em menores distancias do que outras usinas de

Estimativa do Potencial de Geração de Energia Elétrica para diferentes fontes de Biogás no Brasil.

geração de eletricidade, possibilidade de uso em processos de cogeração e redução de odores Porém, há algumas desvantagens que muitas vezes inviabilizama utilização deste gás na produção de energia. O principal problema consiste na geração inconstante de energia, pois a geração de resíduos sofre variações em quantidade, além de que a própria geração de biogás leva algum tempo para atingir seu máximo, iniciando decaimento posteriormente (ROYA et. al.,2007).

Os aterros possuem um limite de vida útil, de forma que deve-se pensarno alto investimento para as instalações de geração de energia e seu destino posterior. O prazo de retorno do investimento dá-se em um longo período dentro do funcionamento do aterro. O mecanismo de armazenamento do biogás é complexo, e embora seja considerada uma energia limpa, há emissão de dióxido de carbono na atmosfera, resultante da combustão do metano, contribuindo em menor escala para o efeito estufa. Há também uma perda considerável de biogás no processo de captação, que escapa para a atmosfera e contribui para o efeito estufa (CENBIO, 2005).

Outros aspectos como a escassez de tecnologias avançadas para otimizar a viabilidade de projetos e sistemas eficientes de limpeza de gases e a falta de fiscalização e de regulamentação especifica prejudicam sua utilidade em aterros brasileiros, pois não existem legislações especificas para a atividade, o que de certa forma pode acarretar em danos ambientais ainda não conhecidos (SALOMON; LORA;2005).

\section{VIABILIDADE}

Devido ao fato do biogás ser considerado leve e de menor densidade é necessário grande volume para seu armazenamento, o que torna inviável sua liquefação, acarretando em dificuldades no transporte e armazenamento (SALOMON; LORA, 2005).

De acordo com Barros e Silva (2013) o Brasil, em 2010 produziu cerca de 20 milhões de toneladas de resíduos urbanos. Se todo esse montante fosse disposto em aterros sanitários, toda matéria orgânica disponível poderia produzir 50TWh de energia. Entretanto, pouco mais de $80 \%$ é depositado em locais indicados, sendo $20 \%$ do total dispostos em lixões a céu aberto. Ao se analisar a viabilidade de empreendimentos observa-se que seria economicamente atrativo apenas para cidades com populações acima de 200 mil habitantes, devido ao montante gerado de resíduos orgânicos urbanos, passível de fácil decomposição e a demanda de energia populacional. Isto ocorre devido ao fato de que a tecnologia de extração do biogás ainda é alta.

Rubio e López-arquillos (2013) sugerem que para se obter a rentabilidade do biogás, são necessários estudos preliminares para a criação de novos aterros com maior capacidade, 
devido a viabilidade na produção de biogás para a geração de energia elétrica, evitando assim problemas relacionados a queima do gás e proporcionando maior rentabilidade em novos empreendimentos. Ao se analisar previamente aspectos de implantação de usinas de cogeração, estas até mesmo, com os lucros alcançados e retorno do investimento, poderiam ajudar a financiar custo de construção feitos nas centrais, poupando o dinheiro da administração pública e beneficiando a população.

Comparando-se o aproveitamento energético da biomassa de resíduos sólidos urbanos, Souza, Horttanainen e Antotonelli (2013) observaram que a alternativa mais viável tanto para a produção de energia, quanto para as variáveis ambientais, é a incineração, pois diminuiria o volume enviado a aterros sanitários, podendo a longo prazo, elimina-los, e também promover geração de eletricidade e calor para industrias, podendo gerar um adicional de renda para os municípios. Esta alternativa é capaz de aumentar o potencial energético, porém torna-se inviável considerando o custo de implantação do sistema.

Murphy e Mckeogh (2004) ao analisar incineração, gaseificação, geração de biogás e utilização em uma produção combinada de calor e energia (CHP), notou que a gaseificação é o processo com maior viabilidade para aterros sanitários devido ao fato de produzir maior quantidade de energia elétrica com menor efeito para o ambiente. Porém, como os demais, esta técnica torna-se inviável ao se considerar os aspectos econômicos.

De acordo com Landin e Azevedo (2008), o sistema de extração completo para uma média de 10 metros de profundidade em um aterro, traria custos de $20 \mathrm{mil} \mathrm{a} 40 \mathrm{mil}$ US\$/ha e o sistema

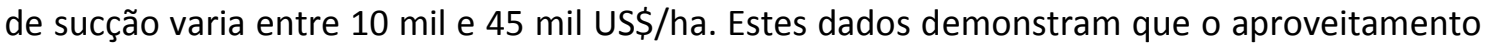
do biogás ainda se apresenta com altos valores, sendo necessárias tecnologias avançadas para sua viabilidade

Existem diversas iniciativas, que pretendem viabilizar a utilização do biogás, Pierobon (2007) estudou um motor de combustão interna acoplado com um motor assíncrono. Este sistema aproveita, de 10,5 a $13,8 \mathrm{~kg} / \mathrm{h}$ de biogás, e para uma geração de $40 \mathrm{~kW}$, o custo, após a instalação do sistema, é de $\mathrm{R} \$ 0,15$ por kwh. $\mathrm{O}$ único empecilho seria a instalação.

\section{MECANISMO DE DESENVOLVIMENTO LIMPO}

Os custos de captação e aproveitamento do biogás são amortizados através de mecanismos de desenvolvimento limpo (MDL), nos quais é possível a venda de créditos de carbono, ou a diminuição da conta de energia elétrica (DUARTE, 2006). Atualmente, a tonelada de $\mathrm{CO}_{2}$ que deixa de ser emitida está sendo cotada em US\$ 8,45 de acordo com Investing (2005).

Assim, os projetos de MDL em aterros sanitários apresentam rentabilidade, pois, países desenvolvidos para cumprir a meta proposta de redução de emissões, compram certificados de redução de países em desenvolvimento. Com estes projetos é possível evitar $80 \%$ de emissão dos gases de efeito estufa, haja visto que a queima dos gases nos aterros, atualmente são efetuadas pelo sistema de flares, tornando assim estes projetos viáveis ambientalmente (PAVAN;PARENTE, 2007).

A implantação de sistemas que visem o aproveitamento do biogás para a energia elétrica possui vantagens ambientais, sociais e econômicas, porém o custo de implantação torna o projeto sem atratividade para empreendedores.Portanto, para que os projetos de MDL realmente possam ser efetivados no Brasil, são necessárias políticas públicas de incentivo, como financiamentos e estudos de viabilidade (CRUZ; PAULINO, 2010). 


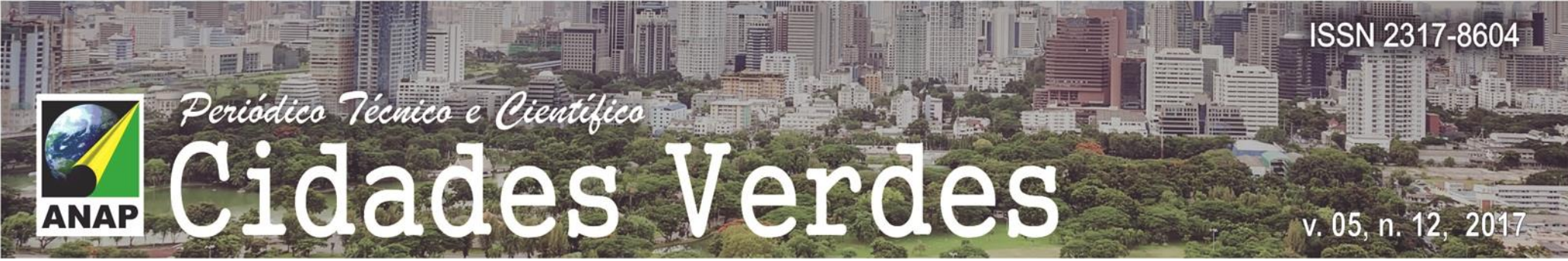

\section{CONCLUSÃO}

A geração de energia elétrica através do biogás de aterros sanitários, ao se analisar o ponto de vista sócio-econômico, e ambiental, apresenta ganhos para a sociedade na geração de empregos, além de ser uma fonte de renda para as prefeituras, através da comercialização de energia, e da troca de créditos de carbono. Entretanto a maior vantagem é no âmbito ambiental, haja visto que através deste processo há uma diminuição de gases de efeito estufa, e ainda é considerada uma energia limpa, diminuindo assim a utilização de combustíveis fosseis para obtenção de eletricidade.

Ao se implantar uma usina de co-geração através do biogás, é importante se levar em consideração a viabilidade econômica do projeto, pois a tecnologia é cara, além de que a produção do biogás é influenciada pela quantidade de lixo disposto e a qualidade destes resíduos.

Com o surgimento de novas tecnologias, é possível que o aproveitamento do biogás se torne viável, porém é fundamental a participação de prefeituras em políticas públicas eficientes de coleta seletiva para melhorar a qualidade do biogás produzido no aterro, além de incentivos financeiros para a implantação de novos projetos.

Portanto, se faz necessário novos estudos nesta área de grande importância ambiental, haja visto que os resíduos sólidos urbanos causam danos ao ambiente, e possuem poder de aproveitamento energético.

Além disso é imprescindível a disseminação de Mecanismos de Desenvolvimento limpo (MDL) e a valorização de créditos de carbono, que podem tornar viável a construção de novos empreendimentos.

\section{AGRADECIMENTOS}

Agradecemos a CAPES e a FAPEMIG pelo apoio financeiro.

\section{REFERÊNCIAS}

ANEEL - Agência Nacional de Energia Elétrica. Banco de Informações de Geração: Usinas do tipo Biomassa em Operação. 2014.

BARROS, Regina M.; TIAGO FILHO, Geraldo L.; SILVA, Tiago R. da. The electric energy potential of landfill biogas in Brazil.Energy Policy, Estados Unidos, v. 1, n. 65, p.150-164, set. 2013.

COELHO, Suzani T; VELÁZQUEZ, Sílvia M. S. G; MARTINS, Osvaldo S. Instalação e testes de uma unidade de demonstração de geração de energia elétrica a partir de biogás de tratamento de esgoto.2004. Disponível em: <http://www.proceedings.scielo.br/scielo.php?pid=MSC0000000022004000200007\&script=sci_arttext>. Acesso em: 11 out. 2015.

COSTA JUNIOR, Nilton.Análise do projeto de uso do biogás no aterro bandeirantes utilizando células combustíveis e queimadores registradores de biogás ecoeficientes.2012. 96 f. Dissertação (Mestrado) - Curso de Engenharia Mecânica, Universidade de Taubaté, Taubaté - SP, 2012.

COSTA, David F. da. Biomassa como fonte de energia, conversão e utilização. (Monografia). Programa Interunidades de Pós-Graduação em Energia (PIPGE) do Instituto de Eletrotécnica e Energia (IEE) da Universidade de São Paulo, São Paulo, 2002. 
